\title{
Incidence of Retinal Detachment in Germany: Results from the Gutenberg Health Study
}

\author{
Eva Gerstenberger $^{a}$ Bernhard Stoffelns ${ }^{a}$ Stefan Nickels ${ }^{a}$ Thomas Münzel ${ }^{b}$ \\ Philipp S. Wild ${ }^{\mathrm{c}-\mathrm{e}}$ Manfred E. Beutel $^{\mathrm{f}}$ Irene Schmidtmann $^{\mathrm{g}}$ Karl J. Lackner ${ }^{\mathrm{h}}$ \\ Norbert Pfeiffer ${ }^{\mathrm{a}} \quad$ Alexander K. Schuster $^{\mathrm{a}}$
}

a Department of Ophthalmology, University Medical Center of the Johannes Gutenberg University Mainz, Mainz,

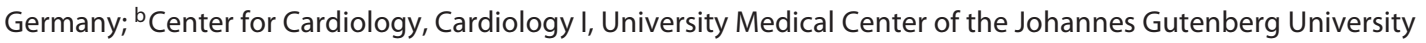
Mainz, Mainz, Germany; ' German Center for Cardiovascular Research (DZHK), Partner Site Rhine-Main, Mainz, Germany; ${ }^{d}$ Preventive Cardiology and Preventive Medicine, Center for Cardiology, University Medical Center of the

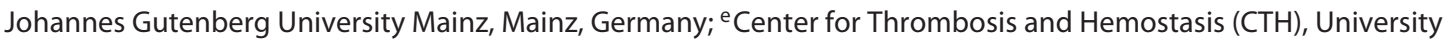

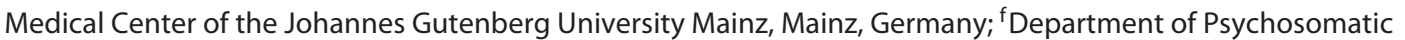
Medicine and Psychotherapy, University Medical Center of the Johannes Gutenberg University Mainz, Mainz, Germany; ${ }^{9}$ Institute of Medical Biostatistics, Epidemiology and Informatics (IMBEI), University Medical Center of the

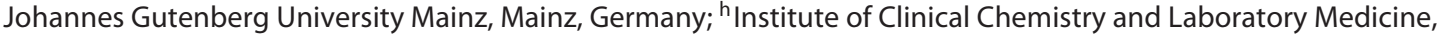
University Medical Center of the Johannes Gutenberg University Mainz, Mainz, Germany

\section{Keywords}

Retinal detachment · Risk factor analysis · Gutenberg Health Study · Population-based cohort study · Epidemiology

\begin{abstract}
Purpose: To investigate the incidence of retinal detachment in the German population and to assess potential risk factors. Methods: The Gutenberg Health Study is a populationbased cohort study in Mainz, Germany, including subjects ( $n=15,010)$ with an age range from 35 to 74 years at baseline examination. Study participants underwent a comprehensive ophthalmological examination including distant-corrected visual acuity, refraction and slit-lamp examination at baseline examination. A computer-assisted telephone interview was conducted after 2.5 and 5 years, and health events were recorded. The 5 -year cumulative incidence of retinal
\end{abstract}

detachment was computed for the study sample and stratified on age decades. Risk factors were analyzed using logistic regression including age, sex, spherical equivalent, pseudophakia and prior laser retinal therapy. Results: 13,416 participants (age $52.2 \pm 10.7$ years, $48.8 \%$ female) were included in this analysis. Twenty-eight subjects had a retinal detachment in one eye, no subject had a retinal detachment in both eyes. The 5-year cumulative incidence of retinal detachment was $0.21 \%(95 \% \mathrm{Cl} 0.14-0.31 \%)$, the incidence rate was $42 / 100,000$ person-years. Risk factors were male sex (OR $4.16, p=0.004)$, pseudophakia (OR 3.93, $p=0.045$ ) and myopia (OR 1.31 per diopter myopia, $p<0.0001$ ), but not prior retinal laser therapy or age. Conclusion: The incidence of retinal detachment in Germany at the age of 35-74 years is comparable to estimates from neighboring European countries. Risk factors are male sex, pseudophakia and myopia.

(c) 2020 S. Karger AG, Basel karger@karger.com

www.karger.com/oph

Karger!
(C) 2020 S. Karger AG, Basel
Alexander Schuster

Department of Ophthalmology, Center for Ophthalmic Epidemiology and Healthcare Research, University Medical Center of the Johannes Gutenberg University Mainz, Langenbeckstraße 1, RLP, DE-55131 Mainz (Germany) alexander.schuster@uni-mainz.de 


\section{Introduction}

Retinal detachment is an ophthalmological emergency and can be differentiated into rhegmatogenous, tractional and exudative types. A rhegmatogenous retinal detachment develops due to a retinal break with inflowing fluid that separates the neurosensory retina and the retinal pigment epithelium. In contrast, proliferative membranes attached to the retina elevate the neurosensory retina in the tractional form.

The incidence of rhegmatogenous retinal detachment varies widely in the literature. A systematic review of population-based studies between 1970 and 2009 showed an average annual incidence of about 10.5 in 100,000 of the population [1] with individual studies ranging from 6.3 [2] to 17.9 [3] per 100,000 persons. The estimates differ in dependence on age range, ethnicity and geographical origin.

The age distribution of rhegmatogenous retinal detachment shows a two-pronged course. The highest incidences are found in the 6th and 7th decades of life, one of the reasons might be the posterior vitreous detachment and vitreous liquefaction [2-16]. A second peak exists in the third decade of life, being associated with myopia [1, 3-6, 9-22].

A certain trend towards higher incidences in the male sex has been demonstrated in various studies $[2-8,10$, $12-14,16-18,23,24]$. Other risk factors are family predisposition $[6,15,19,20]$, summer months [11] and heavy lifting in everyday working life $[4,22]$. As for education and affluence, there are trends towards higher [4] but also lower income and education $[12,22]$ as potential risk factors. Obesity has been found as a risk factor in one study [21], the right eye is described to be affected more often in some studies $[2,6]$. The intake of fluoroquinolones has also been discussed to be associated with an increased risk of retinal detachment [9] but could not be replicated in any other study.

Cataract surgery seems to be a risk factor for rhegmatogenous retinal detachment $[1,3,4,6-9,10,12,18$, $24,25]$. The risk of retinal detachment is described to be 6- to 8 -fold higher after cataract surgery, and a linear increase over a period of 20 years is reported $[1,7,16$, 25].

So far there are no estimates on incidence of retinal detachment in Germany. Therefore, we aim to estimate the incidence of retinal detachment in the context of a large German population-based cohort study and to investigate potential risk factors.

\section{Materials and Methods}

The Gutenberg Health Study (GHS) is a prospective, populationbased cohort study conducted in the Rhine-Main region in Germany. The study sample of 15,010 participants was randomly drawn from local governmental registry offices and equally stratified by sex within each decade of age. More details of the study design are described in Höhn et al. [26]. In brief, the baseline examination was carried out between 2007 and 2012 and the 5-year follow-up examination between 2012 and 2017. The study protocol and documents were approved by the local ethics committee of the Medical Chamber of Rhineland-Palatinate, Germany (reference No. 837.020.07; original vote: March 22, 2007, latest update: October 20, 2015). Written informed consent was obtained from all participants prior to entering them in the study according to the tenets of the Declaration of Helsinki.

\section{Ophthalmological Parameters}

For each participant, an ophthalmological examination was conducted including objective refraction (Humphrey automated refractor/keratometer HARK 599, Carl Zeiss Meditec AG, Jena, Germany) and distance-corrected visual acuity, noncontact tonometry (Nidek NT-2000, Nidek Co., Japan) at baseline and follow-up. Slit-lamp examination of the anterior segment and nonmydriatic fundus photography were performed at baseline. Ophthalmic conditions (e.g., phakia, pseudophakia and aphakia) were documented using standardized documentation sheets, and pseudophakia was validated using refraction and the ophthalmic medical history [27]. Prior eye diseases were recorded as self-report, as was prior retinal laser therapy. The different indications of retinal laser therapy could not be differentiated (e.g., pan-retinal laser coagulation following diabetic changes/thrombosis, central laser coagulation for macular edema or peripheral laser coagulation of tears or degenerative areas).

As part of the study, a computer-assisted telephone interview was conducted after 2.5 years and 5 years, and all health events were recorded. To enhance recall, a booklet was handed out to all study participants to document all health events including inpatient stays in hospitals. In Germany, the statutory health insurance only reimburses procedures for treatment of retinal detachment under inpatient conditions.

Inpatient reports were collected from hospitals and coded according to ICD-10-GM. Rhegmatogenous (H33.0) and tractional retinal detachments (H33.4) were coded separately, as was affected side (right/left eye). In addition, treatment procedures (vitrectomy, scleral buckling) were extracted.

\section{General Parameters}

Diabetes was diagnosed in those individuals with $\mathrm{HbA}_{1 \mathrm{c}}$ $\geq 6.5 \%$, taking diabetic medication or having been diagnosed by a physician. Socioeconomic status was defined according to the index used for the German Health Update 2009 and ranged from 3 to 21 . The type of health insurance (private vs. statutory) was questioned.

Job position was classified via KIdB 2010 ("Klassifikation der Berufe" - German classification of occupation) in 9 categories with additional subgroups for unemployed subjects, retired subjects and homemakers. 
Table 1. Characteristics of the analysis sample with follow-up data on retinal detachment

\begin{tabular}{|c|c|c|c|}
\hline Characteristics & $\begin{array}{l}\text { Overall } \\
(n=13,378)\end{array}$ & $\begin{array}{l}\text { Male } \\
(n=6,702)\end{array}$ & $\begin{array}{l}\text { Female } \\
(n=6,676)\end{array}$ \\
\hline Age (mean, SD), years & $54.66(10.97)$ & $54.90(10.98)$ & $54.41(10.96)$ \\
\hline Sex: female, n (\%) & $6,676(49.9)$ & 0 & 6,676 \\
\hline Hypertension, $\mathrm{n}(\%)$ & $6,505(48.6)$ & $3,597(53.7)$ & $2,908(43.6)$ \\
\hline Diabetes mellitus, $\mathrm{n}(\%)$ & $1,116(8.3)$ & $685(10.2)$ & $431(6.5)$ \\
\hline Body mass index (mean, SD) & $27.25(4.93)$ & $27.79(4.25)$ & $26.71(5.48)$ \\
\hline \multicolumn{4}{|l|}{ Job position } \\
\hline Military, n (\%) & $1(0.0)$ & $1(0.0)$ & $0(0.0)$ \\
\hline $\begin{array}{l}\text { Agriculture, forestry, animal husbandry and } \\
\text { horticulture, } \mathrm{n}(\%)\end{array}$ & & $169(2.5)$ & $60(0.9)$ \\
\hline $\begin{array}{l}\text { Production and manufacturing, } \mathrm{n}(\%) \\
\text { Construction and architecture, surveying and }\end{array}$ & $1,037(7.8)$ & $892(13.3)$ & $145(2.2)$ \\
\hline building technology, $\mathrm{n}(\%)$ & $376(2.8)$ & $348(5.2)$ & $28(0.4)$ \\
\hline Natural and computer science, and geography, n (\%) & $521(3.9)$ & $418(6.3)$ & $103(1.6)$ \\
\hline Transport, logistics and security, $\mathrm{n}(\%)$ & $637(4.8)$ & $482(7.2)$ & $155(2.3)$ \\
\hline $\begin{array}{l}\text { Commercial services and tourism merchandise } \\
\text { trade, hotel, } \mathrm{n}(\%)\end{array}$ & $772(5.8)$ & $347(5.2)$ & $425(6.4)$ \\
\hline $\begin{array}{l}\text { Business organization, accounting, law and } \\
\text { administration, } \mathrm{n}(\%)\end{array}$ & $2,291(17.2)$ & $966(14.5)$ & $1,325(20.0)$ \\
\hline Health and education, social affairs, teaching, $\mathrm{n}(\%)$ & $1,500(11.3)$ & $450(6.7)$ & $1,050(15.8)$ \\
\hline \multicolumn{4}{|l|}{ Humanities, media and culture, design language, } \\
\hline literature, social and economic sciences, art, n (\%) & $732(5.5)$ & $365(5.5)$ & $367(5.5)$ \\
\hline Retired, n (\%) & $3,955(29.7)$ & $2,047(30.6)$ & $1,908(28.7)$ \\
\hline Homemaker, n (\%) & $984(7.4)$ & $44(0.7)$ & $940(14.2)$ \\
\hline Missing data, $\mathrm{n}(\%)$ & $287(2.2)$ & $153(2.3)$ & $134(2.0)$ \\
\hline \multicolumn{4}{|l|}{ Ophthalmological characteristics } \\
\hline logMAR right eye (median, IQR) & $0.00(0.00-0.10)$ & $0.00(0.00-0.10)$ & $0.00(0.00-0.10)$ \\
\hline logMAR left eye (median, IQR) & $0.00(0.00-0.10)$ & $0.00(0.00-0.10)$ & $0.00(0.00-0.10)$ \\
\hline SE right eye (mean, SD), dpt & $-0.47(2.52)$ & $-0.49(2.41)$ & $-0.45(2.63)$ \\
\hline SE left eye (mean, SD), dpt & $-0.46(2.52)$ & $-0.48(2.45)$ & $-0.43(2.59)$ \\
\hline Pseudophakia right eye, $\mathrm{n}(\%)$ & $459(3.4)$ & $211(3.1)$ & $248(3.7)$ \\
\hline Pseudophakia left eye, $\mathrm{n}(\%)$ & $452(3.4)$ & $211(3.1)$ & $241(3.6)$ \\
\hline Retinal laser therapy right eye, $\mathrm{n}(\%)$ & $208(1.6)$ & $108(1.6)$ & $100(1.5)$ \\
\hline Retinal laser therapy left eye, $\mathrm{n}(\%)$ & $235(1.8)$ & $122(1.9)$ & $113(1.7)$ \\
\hline
\end{tabular}

Data from baseline examination (2007-2012) of the German population-based Gutenberg Health Study (2007-2017). SD, standard deviation; IQR, interquartile range; SE, spherical equivalent.

\section{Study Population}

All subjects with a computer-assisted telephone interview at the 5-year follow-up examination were included into the data analysis. Those subjects without collectable inpatient reports of an eye clinic were excluded, if no prior retinal detachment occurred.

\section{Data and Statistical Analysis}

All primary and secondary variables were first tested for normal distribution. Medians, interquartile ranges, minimums and maximums were calculated for all primary and secondary variables. For variables that were normally distributed, means and SD were computed as well. For categorical data, absolute and relative frequencies were calculated.

Five-year cumulative incidence and incidence rate of retinal detachment and its types was computed including 95\% CI. Ageand sex-specific estimates were calculated. Potential risk factors were evaluated using multivariable logistic regression models including age (in decades), sex, diabetes and occupation as covariates in the per-person analysis. For occupation data, homemaker was defined as reference group. Due to small numbers, military, agriculture, natural and computer science, transport, logistics and tourism were denoted, together with unemployment and missing description. The full description and numbers of the categories can be found in Table 1.

A per-eye analysis was conducted using logistic regression analysis incorporating generalized estimating equations and incorporating age, sex, spherical equivalent, lens status (pseudophakia) and self-reported retinal laser treatment as independent variables.

This study was performed as an explorative study to analyze the incidence of retinal detachment in Germany and to investigate potential risk factors associated with this condition. All $p$ values should be regarded as continuous parameters that reflect the level of evidence and are therefore reported exactly. The data were processed using statistical analysis software (R version 3.5.2 [2018-1220]). 
Table 2. Association analysis of incident retinal detachment

\begin{tabular}{|c|c|c|c|c|c|c|}
\hline Parameter $(n=13,378)$ & \multicolumn{3}{|c|}{ Univariate } & \multicolumn{3}{|c|}{ Multivariable } \\
\hline Age (years) & 1.03 & $0.99-1.06$ & 0.56 & 1.02 & $0.96-1.07$ & 0.56 \\
\hline Diabetes yes & 0.84 & $0.20-3.56$ & 0.82 & 0.61 & $0.14-2.63$ & 0.51 \\
\hline \multicolumn{7}{|l|}{ Job position (reference: homemaker) } \\
\hline technology & 1.31 & $0.12-14.5$ & 0.83 & 0.34 & $0.03-4.39$ & 0.41 \\
\hline Business organization, accounting, law and administration & 1.29 & $0.26-6.40$ & 0.76 & 0.60 & $0.11-3.38$ & 0.56 \\
\hline Health and education social affairs, teaching & 0.66 & $0.09-4.66$ & 0.67 & 0.37 & $0.05-2.82$ & 0.34 \\
\hline \multicolumn{7}{|l|}{ Humanities, media and culture, design language, } \\
\hline literature, social and economic sciences, art & 1.35 & $0.19-9.57$ & 0.77 & 0.56 & $0.07-4.48$ & 0.58 \\
\hline Other & 0.39 & $0.06-2.79$ & 0.35 & 0.14 & $0.02-1.14$ & 0.07 \\
\hline
\end{tabular}

Data from the German population-based Gutenberg Health Study (2007-2017). Logistic regression analysis.

\section{Results}

A total of 13,416 study subjects of the original 15,010 subjects (357 died) had a computer-assisted telephone interview 5 years after the baseline examination. Of them, 273 subjects reported 444 hospital stays in ophthalmological departments. 47 (10.6\%) reports of these inpatient's stays were not collectable. Finally, 13,378 subjects were finally included in the analysis of retinal detachment. The effective recruitment efficacy proportion was 55.5\%.

28 subjects had a retinal detachment within the followup of 5 years in one eye, none had a retinal detachment in both eyes. Three of them (11\%) had 2 surgical interventions due to retinal detachment within the 5 years and 1 had 3 interventions (4\%). Twenty-three eyes had a rhegmatogenous retinal detachment (14 right eyes, 9 left eyes), and 5 eyes had a tractional retinal detachment ( 1 right eye, 4 left eyes). Twenty-four eyes were phakic, and 4 eyes were pseudophakic at the baseline examination. In the winter months from December to February, there were 7 cases of retinal detachment, during spring 10 cases, during summer from June to August 4 cases and during fall 7 cases.

The 5-year cumulative incidence of retinal detachment is $0.21 \%$ (95\% CI $0.14-0.31 \%)$. The crude incidence rate is $42 / 100,000$ person-years in our study sample. There is no age dependency but subjects at the age of 5564 years showed descriptively the highest cumulative incidence of retinal detachment within the next 5 years.

In the age group of $35-44$ years, $0.10 \%$ (95\% CI $0.026-$ $0.32 \%$ ) had a retinal detachment; in the group of $45-54$ years, there were $0.22 \%(0.10-0.45 \%)$, in the group of $55-$ 64 years $0.28 \%(0.14-0.53 \%)$, and in the group of $65-74$ years there were $0.22 \%(0.098-0.48 \%)$ subjects with a retinal detachment, respectively.

Logistic regression analyses showed that male sex was independently associated with retinal detachment in the next 5 years (OR 5.05, $p=0.002$ ) while age, diabetes and occupation were not associated (Table 2). Subgroup analysis of cases with only rhegmatogenous retinal detachment revealed similar results (online suppl. Table S1; see www.karger.com/doi/10.1159/000513080 for all online suppl. material).

In the per-eye analysis, retinal detachment was associated with male sex (OR 4.16, $p=0.004$ ), pseudophakia (OR 3.93, $p=0.045$ ) and myopia (OR 1.31 per diopter myopia, $p<0.0001$ ), while not with prior retinal laser therapy and age (Table 3).

\section{Discussion}

The aim of this investigation was to estimate the incidence of retinal detachment in a population-based cohort study in Germany. Up to now, there have only been estimates available based on data of neighboring or other countries $[11,14]$. The 5 -year cumulative incidence of retinal detachment was $0.21 \%$ in our study cohort of subjects aged 35-74 years at inclusion with an incidence rate of $42 / 100,000$ person-years. This is about as much as we expected from a literature review of neighboring countries. 
Table 3. Association analysis of incident retinal detachment

\begin{tabular}{|c|c|c|c|c|c|c|}
\hline \multirow[t]{2}{*}{ Parameter $(n=26,080)$ eyes } & \multicolumn{3}{|c|}{ Univariate } & \multicolumn{3}{|c|}{ Multivariable } \\
\hline & OR & $95 \% \mathrm{CI}$ & $p$ value & OR & $95 \% \mathrm{CI}$ & $p$ value \\
\hline Sex male & 3.67 & $1.46-9.23$ & 0.005 & 4.16 & $1.56-11.1$ & 0.004 \\
\hline Age (years) & 1.03 & $1.00-1.06$ & 0.08 & 1.03 & $0.99-1.08$ & 0.11 \\
\hline Spherical equivalent (in diopters myopia) & 1.26 & $1.20-1.31$ & $<0.0001$ & 1.31 & $1.24-1.38$ & $<0.0001$ \\
\hline Pseudophakia & 4.80 & $1.66-13.8$ & 0.004 & 3.93 & $1.03-15.0$ & 0.045 \\
\hline Retinal laser therapy & 2.22 & $0.30-16.4$ & 0.43 & 0.53 & $0.05-5.32$ & 0.59 \\
\hline
\end{tabular}

Data from the German population-based Gutenberg Health Study (2007-2017). Logistic regression analysis with generalized estimating equations to adjust for inter-eye correlations.

So far, incidence rates of rhegmatogenous retinal detachment range from 9.4 [2] to 18.2 [8] cases per 100,000 person-years in European studies but with a broader age range. The lowest incidence of 9.5/100,000 person-years was found in a British study by Mowatt et al. [2]. This study has been conducted as a retrospective review, analyzing data from 1994 to 1999. Inclusion criteria have been surgically treated rhegmatogenous retinal detachment, exclusion criteria associated proliferative vitreoretinopathy, dialysis without retinal detachment, tractional or exudative retinal detachment and the presence of intraocular foreign bodies [2].

The Dutch study by van de Put et al. [8] showed the highest incidence of $18.2 / 100,000$ person-years. It has been conducted as national multicenter prospective study, analyzing data from 2009. Inclusion criteria have been surgically treated rhegmatogenous retinal detachment, exclusion criteria were tractional, traumatic or exudative retinal detachment [8]. The highest overall incidence, thus in a limited group of study subjects, could be found in the retrospective study by Farioli et al. [22] of a cohort of Swedish men conscripted for compulsory military service born between 1949 and 1951. It showed an incidence of 28 rhegmatogenous retinal detachment cases per 100,000 person-years.

While there are many studies concerning the subform rhegmatogenous retinal detachment, a meta-analysis of Li et al. [14] could not identify any studies reporting the incidence of all total cases of retinal detachments in Europe. Thus, our data fill this gap.

We did not divide the cases of retinal detachment into different subtypes due to the limited number of cases in our study population. Therefore, our numbers are higher than what we presented in the studies discussed above.

Furthermore, our findings might be congruent to a general trend of increasing rates of retinal detachment. So far, for the years 2000-2016, Nielsen's Danish study group described an annual change of retinal detachment in subjects older than 50 years, namely $0.56 / 100,000$ person-years per year in females and 1.67/100,000 person-years per year in males [28]. Mitry et al. [4] described a similar phenomenon with an annual increase of $1.9 \%$ in the age-standardized incidence rate of rhegmatogenous retinal detachment during the time frame from 1987 to 2006 in Scotland.

Since we have very recent data from the years 20072017, there might already be an effect to explain the higher incidence in our study compared to previous studies, but as we did only investigate a 5-year interval, we cannot state on time-dependent change of incidence.

The estimates might also be higher due to an increasing rate of cataract surgery at a younger age, which are reported to be a trend in the Netherlands [1]. Although the Gutenberg Health Study included 15,010 subjects at baseline, the sample size is not as large as registry studies, and therefore the number of cases in each age decade for a relatively rare disease is low. In addition, the age of GHS participants only ranged from 35 to 74 years at study inclusion, and subjects at an older age, especially those previously having had cataract surgery, are not represented in our study. Nevertheless, our study could identify pseudophakia as risk factor for retinal detachment: subjects having had cataract surgery had a 4 -fold increased risk. This in congruence with the literature reporting cataract surgery as a risk factor for retinal detachment. Especially cataract surgery at an early age could be identified as a risk factor for retinal detachment by Kim's Korean and Norregaard's Danish study groups $[12,25]$. Since the absolute frequency of cataract surgery increases in industrialized countries, we might encounter more retinal detachments in our general population in future.

A 2-pronged course of the age distribution of retinal detachment has been identified by various other studies 
with the highest incidences of retinal detachment in the 6th and 7th decades of life [2-16].

A study from New Zealand by Polkinghorne and Craig [18] showed a first peak in the incidence of rhegmatogenous retinal detachment at 20-29 years with approximately an incidence of 9.6/100,000 population. In the age group of 30-39 years, incidence lowered to $4.0 / 100,000$ population. This age group represented the youngest study subjects in our study. A second peak existed at 60-69 years of age with approximately $28 \%$ affected, with an incidence of $49.7 / 100,000$ population [18]. A similar age distribution is reported by Chen et al. [10] in Taiwan. Van de Put et al. [8] reported an incidence of 5.26 per 100,000 people at the age of 35-39 years in the Netherlands. The highest incidence was in the age group of 55-59 years with 52.45/100,000, followed by $51.51 / 100,000$ at the age of 60-64 years.

In contrast, the British study of Mowatt et al. [2] showed a steady rising incidence from 8.7 per 100,000 at the age of $30-39$ up to $29.1 / 100,000$ in those at the age of $70-79$ years in Wolverhamptom. The distribution in Walsall showed $6.8 / 100,000$ at $25-44$ years, with a rising $69.5 / 100,000$ in the age group of 75-84 years, reaching a peak at $98.6 / 100,000$ age-specific demand incidence at 85 years and older [2]. Estimates by Mitry et al. [4] in Scotland are similar, showing a steady rising incidence up to 60-69 years (male 45.85, female 21.40/100,000) without a second peak.

These studies investigate the entire age range of the population, while our study analyzed retinal detachment between 35 and 74 years of age. As reported in these studies, the first peak of incidence in the third decade of life is not represented in our study population. Additionally, our study uses data of all retinal detachment cases, not only specific forms as for example rhegmatogenous retinal detachment.

Myopia is a well-known risk factor for retinal detachment, and in congruence we found an increased risk for myopia of 1.31 per diopter. The Swedish study group of Farioli et al. [21] was able to determine a slowly rising incidence for rhegmatogenous retinal detachment over the age range for emmetropic subjects. The higher the myopia, the earlier the rise of incidence: in subjects with myopia of -3.00 to $-5.75 \mathrm{dpt}$, the incidence peaks to about $25 / 100,000$ person-years at the age of 35-39 years. Subjects with high myopia ( $-6.0 \mathrm{dpt}$ or more) show an early peak of incidence at 25-29 years of age of 60/100,000 person-years, as well as an incidence of over 300/100,000 at the age of 45-49 years [21].

Based on Williams' E3 Study group's estimates [29], approximately 227.2 million people in Europe have myopia. All degrees of myopia showed a higher prevalence in younger study subjects; in middle-aged and older subjects the prevalence was lower except that the oldest subjects showed again an increase in the prevalence of myopia most likely due to cataract development. These data indicate that myopia is increasing in Europe, as Holden's study group postulated [20]. Due to this fact and more and more younger adults affected by myopia, a rise in (rhegmatogenous) retinal detachment is to be expected.

We were able to identify male sex as risk factor for rhegmatogenous retinal detachment, according to what the literature suggests so far $[2-8,10,12,13,15-18,24$, $25]$. This might be due to hormonal or genetic reasons, as various other studies described men as more prone to rhegmatogenous retinal detachment than women; we had a 4 -fold higher rate in males. Another factor might be different occupation or lifestyle behavior.

Chen's study group [10] was able to define 2 different gender-related risks of retinal detachment: the first peak of incidence of 15/100,000 person-years has been found in females at 20-29 years of age. After this age, men have an increased incidence with a peak at 50-59 years (about $50 / 100,000$ person-years), while women have an incidence of approximately 30/100,000 [10]. In contrast, Mitry's study group [4] reported a higher overall incidence in male subjects. At the age of 20-29 years, the annual incidence was similar between males and females but showed an increasing difference with aging up to the age of 60-69 years: in this age group the incidence was $45.85 / 100,000$ in males, while females showed an incidence of 21.40/100,000 [4].

Our study has several limitations. First, our study sample of 15,010 subjects at baseline examination is small for a relatively rare disease such as retinal detachment and the age range is only from 35 to 74 years of age at inclusion. Therefore, our results are only valid for this age range. Second, we were not able to distinguish between different subtypes of retinal detachment as the incident cases were too few. Third, we were not able to collect $10.6 \%$ of inpatient reports of eye clinics, and therefore a few cases might not have been detected. Since the treatment options of retinal detachment are only refunded in the case of an inpatient stay in Germany, we did not include self-reports of study participants but validated data of inpatient reports. Lastly, our study data do not distinguish between different types of laser therapy performed (e.g., panretinal laser coagulation following diabetic changes/thrombosis, central laser coagulation for macular edema or peripheral laser coagulation of holes or degenerative areas), and results might be different if these entities are analyzed separately. 
In conclusion, incidence of retinal detachment in Germany at the age of 35-74 years is comparable to estimates from neighboring European countries. Risk factors are male sex, pseudophakia and myopia.

\section{Acknowledgment}

G.H.S. thanks all participants who took part in this study and the whole G.H.S. team, which includes study assistants, interviewers, computer and laboratory technicians, research scientists, managers and statisticians.

\section{Statement of Ethics}

The study protocol and documents were approved by the local ethics committee of the Medical Chamber of Rhineland-Palatinate, Germany (reference no. 837.020.07; original vote: 22.3.2007, latest update: 20.10 .2015$)$. Written informed consent was obtained from all participants prior to entering them in the study according to the tenets of the Declaration of Helsinki.

\section{Conflict of Interest Statement}

The authors declare that they have no competing interests. Boehringer Ingelheim, Philips Medical Systems and Novartis Pharma provided funding towards this study. There are no patents, products in development or marketed products to declare. The funders had no role in study design, data collection and analysis, decision to publish or preparation of the manuscript.

N.P. receives financial support and grants from Novartis, Ivantis, Santen, Thea, Boehringer Ingelheim Deutschland GmbH \& Co. KG, Alcon, and Sanoculis. M.E.B. received a speaker honorarium from Pfizer Deutschland GmbH, Shire Deutschland GmbH and currently receives research grants from the governments of Rhineland-Palatinate and Nordrhein-Westfalen, the German Association of Psychoanalysis and Psychotherapy (DGPT), the German Research Foundation, the German Ministry of Research, the German Cancer Aid and the European Union. A.K.S. received financial and research support by Allergan, Heidelberg Engineering, Novartis, Bayer Vital and PlusOptix.

S.N. is a scientific consultant (freelance) for IQVIA Commercial GmbH \& Co. OHG, Frankfurt/Main, Germany.

T.M., K.J.L., P.S.W., B.S., I.S., E.G.: none.

\section{Funding Source}

All authors: The Gutenberg Health Study is funded through the government of Rhineland-Palatinate ("Stiftung Rheinland-Pfalz für Innovation," contract AZ 961-386261/733), the research programs "Wissen schafft Zukunft" and "Center for Translational Vascular Biology (CTVB)" of the Johannes Gutenberg University of Mainz, and its contract with Boehringer Ingelheim and Philips
Medical Systems, including an unrestricted grant for the Gutenberg Health Study. Funders were involved in the development of the study design as scientific consultants. The funders had no role in study design, data collection and analysis, decision to publish or preparation of the manuscript.

P.S.W. is funded by the Federal Ministry of Education and Research (BMBF 01EO1503) and he is the PI of the German Center for Cardiovascular Research (DZHK). N.P. receives financial support from Novartis, Ivantis, Santen, Thea, Boehringer Ingelheim Deutschland GmbH and Co. KG, Alcon and Sanoculis. M.E.B. received a speaker honorarium from Pfizer Deutschland $\mathrm{GmbH}$, Shire Deutschland $\mathrm{GmbH}$ and currently receives research grants from the governments of Rhineland-Palatinate and NordrheinWestfalen, the German Association of Psychoanalysis and Psychotherapy (DGPT), the German Research Foundation, the German Ministry of Research, the German Cancer Aid and the European Union. A.K.S. holds the professorship for ophthalmic health care research endowed by "Stiftung Auge" and financed by "Deutsche Ophthalmologische Gesellschaft" and "Berufsverband der Augenärzte Deutschland e.V.”

T.M., K.J.L., B.S., I.S., E.G.: none.

\section{Author Contributions}

E.G., S.N., and A.K.S. conceived and designed the study. E.G., S.N. and A.K.S. analyzed the data. E.G. wrote the paper. B.S., S.N., T.M., E.G., P.S.W., M.E.B., I.S., K.J.L, N.P., and A.K.S. critically revised the paper. All authors read and approved the final paper.

\section{Access to Data, Responsibility and Analysis}

E.G., S.N., and A.K.S. had full access to all the data in the study and take responsibility for the integrity of the data and the accuracy of the data analysis. Statistical analyses were performed by A.K.S.

The analysis presents clinical data of a large-scale populationbased cohort with ongoing follow-up examinations. This project constitutes a major scientific effort with high methodological standards and detailed guidelines for analysis and publication to ensure scientific analyses on the highest level. Therefore, data are not made available for the scientific community outside the established and controlled workflows and algorithms. To meet the general idea of verification and reproducibility of scientific findings, we offer access to data at the local database in accordance with the ethics vote upon request at any time. The GHS steering committee, which comprises a member of each involved department and the coordinating PI of the Gutenberg Health Study (PSW), convenes once a month. The steering committee decides on internal and external access of researchers and use of the data and biomaterials based on a research proposal to be supplied by the researcher. Interested researchers make their requests to the coordinating PI of the Gutenberg Health Study (Philipp S. Wild; philipp.wild@unimedizin-mainz.de). More detailed contact information is available at the homepages of the GHS. 


\section{References}

1 Mitry D, Charteris DG, Fleck BW, Campbell $\mathrm{H}$, Singh J. The epidemiology of rhegmatogenous retinal detachment: geographical variation and clinical associations. Br J Ophthalmol. 2010 Jun;94(6):678-84.

2 Mowatt L, Shun-Shin G, Price N. Ethnic differences in the demand incidence of retinal detachments in two districts in the West Midlands. Eye (Lond). 2003 Jan;17(1):63-70.

3 Rowe JA, Erie JC, Baratz KH, Hodge DO, Gray DT, Butterfield L, et al. Retinal detachment in Olmsted County, Minnesota, 1976 through 1995. Ophthalmology. 1999 Jan; 106(1):154-9.

4 Mitry D, Charteris DG, Yorston D, Siddiqui MA, Campbell H, Murphy AL, et al.; Scottish RD Study Group. The epidemiology and socioeconomic associations of retinal detachment in Scotland: a two-year prospective population-based study. Invest Ophthalmol Vis Sci. 2010 Oct;51(10):4963-8.

5 Mitry D, Chalmers J, Anderson K, Williams L, Fleck BW, Wright A, et al. Temporal trends in retinal detachment incidence in Scotland between 1987 and 2006. Br J Ophthalmol. 2011 Mar;95(3):365-9.

6 Mitry D, Singh J, Yorston D, Siddiqui MA, Wright A, Fleck BW, et al. The predisposing pathology and clinical characteristics in the Scottish retinal detachment study. Ophthalmology. 2011 Jul;118(7):1429-34.

7 Bjerrum SS, Mikkelsen KL, La Cour M. Risk of pseudophakic retinal detachment in 202,226 patients using the fellow nonoperated eye as reference. Ophthalmology. 2013 Dec; 120(12):2573-9.

8 Van de Put MA, Hooymans JM, Los LI; Dutch Rhegmatogenous Retinal Detachment Study Group. The incidence of rhegmatogenous retinal detachment in The Netherlands. Ophthalmology. 2013 Mar;120(3):616-22.

9 Feltgen N, Walter P. Rhegmatogenous retinal detachment - an ophthalmologic emergency. Dtsch Arztebl Int. 2014 Jan;111(1-2):12-21.

10 Chen SN, Lian IB, Wei YJ. Epidemiology and clinical characteristics of rhegmatogenous retinal detachment in Taiwan. Br J Ophthalmol. 2016 Sep;100(9):1216-20.
11 Bechrakis NE, Dimmer A. [Rhegmatogenous retinal detachment: epidemiology and risk factors]. Ophthalmologe. 2018 Feb;115(2): 163-78.

12 Kim J, Ryu SY, Hong JH, Chung EJ. Incidence and risk factors for retinal detachment after cataract surgery in Korea: a nationwide population-based study from 2011 to 2015. Graefes Arch Clin Exp Ophthalmol. 2019 Oct; 257(10):2193-202.

13 Kim MS, Park SJ, Park KH, Woo SJ. Different Mechanistic Association of Myopia with Rhegmatogenous Retinal Detachment between Young and Elderly Patients. BioMed Res Int. 2019 Aug;2019:5357241.

14 Li JQ, Welchowski T, Schmid M, Holz FG, Finger RP. Incidence of Rhegmatogenous Retinal Detachment in Europe - A Systematic Review and Meta-Analysis. Ophthalmologica. 2019;242(2):81-6.

15 Boutin TS, Charteris DG, Chandra A, Campbell S, Hayward C, Campbell A, et al.; UK Biobank Eye \& Vision Consortium; 23andMe Research Team. Insights into the genetic basis of retinal detachment. Hum Mol Genet. 2020 Mar;29(4):689-702.

16 Qureshi MH, Steel DH. Retinal detachment following cataract phacoemulsification - a review of the literature. Eye (Lond). 2020 Apr; 34(4):616-31.

17 Algvere PV, Jahnberg P, Textorius O. The Swedish Retinal Detachment Register. I. A database for epidemiological and clinical studies. Graefes Arch Clin Exp Ophthalmol. 1999 Feb;237(2):137-44

18 Polkinghorne PJ, Craig JP. Northern New Zealand Rhegmatogenous Retinal Detachment Study: epidemiology and risk factors. Clin Exp Ophthalmol. 2004 Apr;32(2):15963.

19 Go SL, Hoyng CB, Klaver CC. Genetic risk of rhegmatogenous retinal detachment: a familial aggregation study. Arch Ophthalmol. 2005 Sep;123(9):1237-41.

20 Holden BA, Fricke TR, Wilson DA, Jong M, Naidoo KS, Sankaridurg P, Wong Ty, Naduvilath TJ, Resnikoff S. Global prevalence of myopia and high myopia and temporal trends from 2000 through 2050. Ophthalmology. 2016 May;123(5):1036-42.

21 Farioli A, Hemmingsson T, Kriebel D. Vascular risk factors and rhegmatogenous retinal detachment: a follow-up of a national cohort of Swedish men. Br J Ophthalmol. 2016 Jul; 100(7):907-13.

22 Farioli A, Kriebel D, Mattioli S, Kjellberg K, Hemmingsson T. Occupational lifting and rhegmatogenous retinal detachment: a follow-up study of Swedish conscripts. Occup Environ Med. 2017 Jul;74(7):489-95.

23 Haimann MH, Burton TC, Brown CK. Epidemiology of retinal detachment. Arch Ophthalmol. 1982 Feb;100(2):289-92.

24 Hajari JN, Bjerrum SS, Christensen U, Kiilgaard JF, Bek T, la Cour M. A nationwide study on the incidence of rhegmatogenous retinal detachment in Denmark, with emphasis on the risk of the fellow eye. Retina. 2014 Aug;34(8):1658-65.

25 Norregaard JC, Thoning H, Andersen TF, Bernth-Petersen P, Javitt JC, Anderson GF. Risk of retinal detachment following cataract extraction: results from the International Cataract Surgery Outcomes Study. Br J Ophthalmol. 1996 Aug;80(8):689-93.

26 Höhn R, Kottler U, Peto T, Blettner M, Münzel T, Blankenberg S, et al. The ophthalmic branch of the Gutenberg Health Study: study design, cohort profile and self-reported diseases. PLoS One. 2015 Mar;10(3):e0120476.

27 Schuster AK, Pfeiffer N, Schulz A, Nickels S, Höhn R, Wild PS, et al. The impact of pseudophakia on vision-related quality of life in the general population - The Gutenberg Health Study. Aging (Albany NY). 2017 Mar; 9(3):1030-40.

28 Nielsen BR, Alberti M, Bjerrum SS, la Cour M. The incidence of rhegmatogenous retinal detachment is increasing. Acta Ophthalmol. 2020 Sep;98(6):603-6.

29 Williams KM, Verhoeven VJ, Cumberland P, Bertelsen G, Wolfram C, Buitendijk GH, et al. Prevalence of refractive error in Europe: the European Eye Epidemiology (E(3)) Consortium. Eur J Epidemiol. 2015 Apr;30(4):30515. 